\title{
Effect of Implementing Nursing Instructions on Minimizing Bleeding Among Patients with Acute Myeloid Leukemia.
}

\author{
Mona Mohammed Abdel Haady ${ }^{1}$, Olfat Abd El-Ghany Shawer ${ }^{2}$, Mervat Anwar Abdel-Aziz ${ }^{3}$. \\ 1. \\ 2. Specialist nursing, Faculty of Nursing, South Egypt Cancer Institute, Assiut University, Assiut, Egypt. \\ 2. Assistant Professor of Critical \& Emergency Care Nursing, Faculty of Nursing, Assiut University, Assiut, Egypt. \\ 3. Assistant Professor of Critical \& Emergency Care Nursing, Faculty of Nursing, Assiut University, Assiut, Egypt
}

\begin{abstract}
Background Patients with Acute myeloid leukemia are at risk of bleeding that may cause life-threatening and death Aim: To investigate the effect of implementing nursing instructions on minimize bleeding among patients with Acute Myeloid Leukemia. Study design: Quasi experimental research design was utilized in this study. Setting: The study was conducted in the critical care unit at south Egypt cancer institute at Assiut University hospital. Sample: A convenient sample of 60 adult patients divided randomly into (30 study and 30 control) groups. Tools: Two tools used for data collection, tool (I);An interview questionnaire, tool (II); assessment of bleeding tendency. Results: There was a statistical difference between study and control group regarding whole blood and amount of blood loss according to class of hemorrhagic Shock in addition this amount decreased after implementation of nursing instructions at $3^{\text {rd }}$ and $5^{\text {th }}$ day with P.value (0.008). Conclusion: This study confirmed our hypothesis that implementing of nursing instructions on the patients with acute myeloid leukemia leading to minimize bleeding. Recommendation: Continued nursing instructions at critical care units should be organized within south Egypt cancer institute.
\end{abstract}

\section{Keywords: Acute Myeloid Leukemia, Bleeding \& Nursing Instructions.}

\section{Introduction}

Acute myeloid leukemia (AML) is characterized by uncontrolled proliferation of myoblasts. There is hyperplasia of the bone marrow. The clinical manifestations are usually related to the replacement of normal hematopoietic cells in the marrow by leukemic myoblasts and, to infiltration of other organs and tissue (Lewis et al., 2015).

Bleeding and thrombosis are major risk factors for early death in patients with acute leukemia; chemotherapy increases the likelihood of both of these complications. Patients with acute leukemia often present with a hyper-coagulable state or with evidence for chronic disseminated intravascular coagulation, even in the absence of active thrombosis and/or bleeding (Iliescu et al., 2016).

The early signs of AML are often vague and nonspecific, Some generalized symptoms include fever, fatigue, weight loss or loss of appetite, shortness of breath, anemia, easy bruising or bleeding, petechia (flat, pin-head sized spots under the skin caused by bleeding) (Hatzl et al., 2018).

The first clue to a diagnosis of AML is typically an abnormal result on a complete blood count. AML can also present with isolated decreases in platelets, red blood cells, or even with a low white blood cell count (leukopenia) (Leguit \& Van, 2010)
The complications of AML include bleeding and infection, which are the major causes of death. The risk of bleeding correlates with the level and duration of platelet deficiency (thrombocytopenia). The low platelet count can cause ecchymoses (bruises) and petechiae. Major hemorrhage also may develop when the platelet count drops to less than $10,000 / \mathrm{mm}^{3}$. The most common bleeding sources include gastrointestinal (GI), pulmonary, vaginal, and intracranial. Disseminated intravascular coagulopathy (DIC) is common, particularly in patients with Acute Promyelocytic Leukemia (APL) For undetermined reasons, fever and infection also increase the likelihood of bleeding (Janice \& Kerry, 2014)

Measures to prevent tissue injury, bleeding e.g., gentle brushing of teeth or gums with a soft toothbrush, cotton swab, or sponge-tipped applicator4using electric razor instead of sharp one when shaving avoiding forceful nose blowing and needle sticks when possible using sustained pressure(sandbags or pressure dressings) on oozing puncture sites. Limited oral care to a mouth rinse if indicated and avoid mouthwashes with alcohol and avoid hard diet (Deep \& Bunchman, 2015). 
Nursing instructions should focus on identifying the underlying cause(s) and, where possible, controlling the bleeding. A comprehensive history and examination are self-evident. A review of concurrent medications and other illnesses may be help identify the etiology, or contribute factors such as the concurrent use of nonsteroidal anti-inflammatory drugs, which may exacerbate or precipitate bleeding through their actions on the gastrointestinal tract and platelet functioning (Munshi et al., 2016).

\section{Significance of the study}

According to statistical reports of hematological malignancy at south Egypt cancer Institute, (2017) documented that 430 cases diagnosed with acute myeloid leukemia (AML). It was observed that $80 \%$ of patients complain of increase bleeding tendency. Therefore, they need special instructions to minimize bleeding. Therefore, the study aimed to determine the effect of implementing nursing instructions on bleeding among patients with acute myeloid leukemia at intensive care unit.

\section{Aim of the study}

The aim of the study is to investigate the effect of implementing nursing instructions on minimizing bleeding among patients with Acute Myeloid Leukemia admitted to the intensive care unit.

\section{Research hypothesis}

- The bleeding tendency in study group who will receive nursing instructions will be less than control group who receive routine care at ICU.

\section{Subjects \& Methods}

Research design: Quasi-experimental research design was utilized in this study.

Setting: The study was conducted in the critical care unit at south Egypt cancer institute at Assiut University hospital.

Sample:

- A convenient sample of 60 adult patients (both sex) with acute myeloid leukemia in ICU, who have bleeding, was included in the study.

- They were divided randomly into two equal groups (30 patients as a control group who received routine care and 30 as a study group who received nursing instructions).

Tools of data collection

Tool (I):An interview questionnaire: This sheet was developed by the researcher based on literature review this tool was include three parts:

Part (1): Socio-demographic and medical data: It includes the patient's (name, age, gender) and medical data such as: (past health history) it was collected once the patient admitted to the ICU.

Part (2): Laboratory Investigation

This part aimed to assess laboratory investigations which included: Complete blood count (RBCs, Hgb level, HCT, PLT Count, WBCs), coagulation profile (Prothrombin time (PT), Prothrombin concentration(pc), INR).

These investigations were obtained on admission, after application of the nursing instructions then every day for the following four days for both groups. Part (3): Assessment of hemodynamic parameters: This part aimed to assess the hemodynamic status, which include vital signs; (heart rate, systolic and diastolic blood pressure).

These parameters were obtained on admission, after application of the nursing instructions then every day for the following four days for both groups.

Tool (II): Assessment of bleeding tendency

This tool aimed to evaluate the effect of nursing instructions on minimizing bleeding. assess bleeding tendency, types and amount of blood loss according to shock classes.

This sheet were utilized on admission, after application of the nursing instructions then every day for the following four days for both groups.

\section{Implementing nursing instructions}

It developed by the researchers after reviewing national and international literature, researcher experience and opinions and as regard patients' needs. nursing instructions measures for assessing and managing bleeding risk among patients with AML. It was concerning knowledge about a brief illustration of the following items:

Avoid of bleeding through the following; Packing can be used with or without pressure to achieve hemostasis when bleeding originates in the nose, vagina, or rectum, use soft toothbrush, shave with electric razor only to prevents trauma to skin, use emery board for nail care, lubricate lips with petrolatum to prevent skin from drying, avoid foods that are difficult to chew to prevent oral tissue trauma, provide skin care by keeping patients skin clean, avoid medications that will interfere with clotting, increase fiber in diet to prevent constipation, caution against forceful nose blowing, avoidance strenuous activity that increase intracranial pressure and risk of cerebral hemorrhage, and etc.....

The nursing instructions was revised and modified based on the expertise comments. It was written in Arabic using simple language with illustrations and was modified by the investigator supported with colored pictures. It was concerning knowledge about the bleeding among patients with acute myeloid leukemia as identification of types of bleeding, 
causes, signs and symptoms, complications, prevention and treatment.

\section{Technique for data collection}

\section{Methods}

The study was conducted throughout three main phases, which include:

1-Preparatory phase: This phase was involved:

Official permission to conduct the study was obtained from the hospital responsible authorities and unit of treatment of hematological malignancy after explaining the aim of the study.

Development of tools (I and II) after reviewing the related national and international literature.

Content validity; the tools were tested for content validity by jury of (5) experts in the field of critical care nursing and critical care medicine from Assiut university hospital and the necessary modification were done.

\section{Pilot study}

Carried out on ten percentage (6) patient who met the predetermined selection criteria to assess the clarity and applicability of the tools.

\section{2- Implementation phase}

- The studied patients were given an educational booklet in clear Arabic language; which included nursing instructions for patients with AML.

- Number of session (ten session), every session include 6 patients, each session took about 30-40 min and study was carried out in the morning shift from 8 am to $2 \mathrm{pm}$.

- Each session contain the following items: types of bleeding, causes, signs and symptoms, complications, prevention and treatment.

- Implementing nursing instructions were applied on an individual basis, one of the family members attended the session to confirm patients support and increasing their sense of responsibility.

- After each session there was 5-10 min for discussion and feedback.

- The researcher used pictures to help them retain the learned material.

- Data was assured anonymity and confidentiality and were collected using the study tools.

- Group of patients was given the freedom to choose their optimal time for receiving the instructions whenever they have minimal discomforts and not in treatment time.

- Tool I (part 2 and 3) and tool (II) were used before and immediately after the implementation of the nursing instructions as well as for four days later to evaluate the effect of the nursing instructions on bleeding tendency.

3- Evaluation phase

- The last phase of the proposed nursing instructions was the evaluation phase. In which the study and control groups were followed up to evaluate effects of implementing nursing instructions on patients and to insist on participant's compliance with the given instructions.

- The control group: The researcher assessed critically ill patients with AML who receive routine care for the $1^{\text {st }}$ day on admission and consequently daily for five days using a tool I \&II.

\section{Ethical considerations}

- Research proposal approved from the ethics committee in the Faculty of Nursing, Assiut University.

- There is no risk for study subject during application of the research.

- The study followed common ethical- principles in clinical research.

- Informed consent was obtained from patients or guidance that is willing to participate in the study after explaining the nature and purpose of the study.

- Confidentiality and anonymity assured.

- Patients had the right to refuse to participate and or withdraw from the study without any rational any time.

- Patient privacy was considered during the collection of data.

\section{Statistical analysis}

Collected data were analyzed and tabulated. The researcher used an appropriate statistical method and tests for analysis of the result. The statistical Package for (SPSS) version (23) was used to analyze data. 
Results

Table (1):Distribution of Socio demographic data according to group $(n=60)$.

\begin{tabular}{|c|c|c|c|c|c|}
\hline \multirow{2}{*}{ Socio demographic data } & \multicolumn{2}{|c|}{$\operatorname{Study}(n=30)$} & \multicolumn{2}{|c|}{$\operatorname{Control}(n=30)$} & \multirow{2}{*}{ P. value } \\
\hline & n. & $\%$ & n. & $\%$ & \\
\hline \multicolumn{6}{|l|}{ Age group } \\
\hline$<20$ years & 6 & 20 & 2 & 7 & \multirow{4}{*}{0.308} \\
\hline $20-<40$ years & 6 & 20 & 4 & 13 & \\
\hline $40 \geq 50$ years & 6 & 20 & 6 & 20 & \\
\hline More than 50 years & 12 & 40 & 18 & 60 & \\
\hline Mean \pm SD & \multicolumn{2}{|c|}{$44.60 \pm 9.66$} & \multicolumn{2}{|c|}{$48.8 \pm 11.02$} & 0.090 \\
\hline \multicolumn{6}{|l|}{ Gender } \\
\hline Male & 16 & 53.3 & 10 & 33.3 & \multirow{2}{*}{0.118} \\
\hline Female & 14 & 46.7 & 20 & 66.7 & \\
\hline
\end{tabular}

Chi-square test $p$. value $<0.05$

Table(2):Relationship between study and control group according to medical data post implementation of nursing instructions $(n=60)$.

\begin{tabular}{|l|l|l|l|l|l|}
\hline \multirow{2}{*}{\multicolumn{1}{c|}{ medical data }} & \multicolumn{2}{c|}{ Study(n=30) } & \multicolumn{2}{c|}{ Control(n=30) } & \multirow{2}{*}{ P. value } \\
\cline { 2 - 7 } & \multicolumn{1}{|c|}{ n. } & \multicolumn{2}{c|}{ n. } & \multicolumn{2}{c|}{} \\
\hline Past health history: & & & & & \\
\hline Hypertension & 18 & 60.0 & 16 & 53.3 & 0.602 \\
\hline Diabetes mellitus & 10 & 33.3 & 16 & 53.3 & 0.118 \\
\hline Respiratory disease & 30 & 100.0 & 26 & 86.7 & $0.038^{*}$ \\
\hline Renal disease & 0 & 0.0 & 2 & 6.7 & 0.150 \\
\hline Other & 0 & 0.0 & 2 & 6.7 & 0.150 \\
\hline
\end{tabular}

Chi-square test $p$. value $<0.05 *$ statistically significant $* *$ highly significant

Table(3): Relationship between (Study \& Control group) according to blood picture post implementation of nursing instructions $(\mathbf{n}=60)$.

\begin{tabular}{|c|c|c|c|}
\hline \multirow{2}{*}{ Blood picture: } & $\operatorname{Study}(n=30)$ & Control(n=30) & \multirow{2}{*}{ P.value } \\
\hline & Mean \pm SD & Mean \pm SD & \\
\hline \multicolumn{4}{|l|}{ Red blood cell count } \\
\hline $1^{\text {st }}$ day & $3.53 \pm 0.69$ & $3.63 \pm 0.63$ & 0.534 \\
\hline $3^{\text {rd }}$ day & $3.92 \pm 0.43$ & $3.77 \pm 0.7$ & 0.308 \\
\hline $5^{\text {th }}$ day & $4.35 \pm 0.36$ & $3.81 \pm 0.6$ & $<0.001 * *$ \\
\hline \multicolumn{4}{|l|}{ Hemoglobin } \\
\hline $1^{\text {st }}$ day & $8.63 \pm 1.12$ & $9.49 \pm 1.97$ & $0.042 *$ \\
\hline $3^{\text {rd }}$ day & $10.49 \pm 0.87$ & $10.21 \pm 1.4$ & 0.36 \\
\hline $5^{\text {th }}$ day & $11.35 \pm 0.68$ & $10.62 \pm 1.34$ & $0.014 *$ \\
\hline \multicolumn{4}{|l|}{ Hematocrit } \\
\hline $1^{\text {st }}$ day & $30.61 \pm 5.71$ & $31.53 \pm 6.51$ & 0.563 \\
\hline $3^{\text {rd }}$ day & $34.14 \pm 4.39$ & $31.84 \pm 6.53$ & 0.115 \\
\hline $5^{\text {th }}$ day & $37.58 \pm 2.93$ & $33.64 \pm 5.65$ & $0.001 * *$ \\
\hline \multicolumn{4}{|l|}{ Platelet count } \\
\hline $1^{\text {st }}$ day & $45.13 \pm 27.95$ & $96.19 \pm 75.99$ & $0.001 * *$ \\
\hline $3^{\text {rd day }}$ & $63.73 \pm 28.17$ & $89.47 \pm 68.1$ & 0.061 \\
\hline $5^{\text {th }}$ day & $87.81 \pm 33.94$ & $101.79 \pm 83.27$ & 0.401 \\
\hline \multicolumn{4}{|l|}{ White blood cell count } \\
\hline $1^{\text {st }}$ day & $14.71 \pm 22.67$ & $44.86 \pm 92.15$ & 0.087 \\
\hline $3^{\text {rd }}$ day & $14.16 \pm 21.35$ & $51.36 \pm 104.53$ & 0.061 \\
\hline $5^{\text {th }}$ day & $8.14 \pm 4.55$ & $12 \pm 8.38$ & $0.041 *$ \\
\hline
\end{tabular}


Table(4):Relationship between (Study \& Control group) according to coagulation Profile post implementation of nursing instructions $(n=60)$.

\begin{tabular}{|l|c|c|c|}
\hline \multirow{2}{*}{ Coagulation Profile } & Study(n=30) & Control(n=30) & \multirow{2}{*}{ P.value } \\
\cline { 2 - 3 } & Mean \pm SD & Mean \pm SD & \\
\hline $\mathbf{P t}$ & & & 0.737 \\
\hline $1^{\text {st }}$ day & $21.09 \pm 14.69$ & $20.07 \pm 7.67$ & 0.868 \\
\hline $3^{\text {rd }}$ day & $18.58 \pm 9.81$ & $18.96 \pm 7.69$ & 0.297 \\
\hline $5^{\text {th }}$ day & $13.79 \pm 2.5$ & $14.52 \pm 2.21$ & \\
\hline Pc & & & 0.412 \\
\hline $1^{\text {st }}$ day & $60.47 \pm 13.75$ & $57.43 \pm 14.67$ & 0.16 \\
\hline $3^{\text {rd }}$ day & $70.41 \pm 7.7$ & $65.66 \pm 16.47$ & $0.011^{*}$ \\
\hline $5^{\text {th }}$ day & $72.49 \pm 3.78$ & $65.39 \pm 13.97$ & \\
\hline INR & & & 0.34 \\
\hline $1^{\text {st }}$ day & $1.41 \pm 0.31$ & $1.51 \pm 0.49$ & $0.046^{*}$ \\
\hline $3^{\text {rd }}$ day & $1.32 \pm 0.22$ & $1.58 \pm 0.65$ & $0.001^{* *}$ \\
\hline $5^{\text {th }}$ day & $1.15 \pm 0.12$ & $1.36 \pm 0.27$ & \\
\hline
\end{tabular}

Chi-square test $p$. value $<0.05 \quad *$ statistically significant $* *$ highly significant

Pt: Prothrombin time Pc: Prothrombin concentration INR: international normalized ratio

Table(5):Relationship between(Study \& Control group)according to hemodynamic Parameter post implementation of nursing instructions.

\begin{tabular}{|c|c|c|c|}
\hline \multirow{2}{*}{$\begin{array}{l}\text { Hemodynamic } \\
\text { Parameter: }\end{array}$} & $\operatorname{Study}(n=30)$ & Control(n=30) & \multirow{2}{*}{ P. value } \\
\hline & Mean \pm SD & Mean \pm SD & \\
\hline \multicolumn{4}{|l|}{ Heart rate } \\
\hline $1^{\text {st }}$ day & $114.8 \pm 16.27$ & $111.47 \pm 17.91$ & 0.454 \\
\hline $3^{\text {rd }}$ day & $113.2 \pm 15.95$ & $110.73 \pm 13.04$ & 0.515 \\
\hline $5^{\text {th }}$ day & $120.23 \pm 14.02$ & $116.93 \pm 9.9$ & 0.297 \\
\hline \multicolumn{4}{|l|}{ Systolic BP } \\
\hline $1^{\text {st }}$ day & $135.33 \pm 26.49$ & $131.33 \pm 27$ & 0.565 \\
\hline $3^{\text {rd }}$ day & $122.53 \pm 10.98$ & $118 \pm 17.89$ & 0.242 \\
\hline $5^{\text {th }}$ day & $113.8 \pm 5.2$ & $119.17 \pm 11.39$ & $0.025^{*}$ \\
\hline \multicolumn{4}{|l|}{ Diastolic BP } \\
\hline $1^{\text {st }}$ day & $85.33 \pm 16.97$ & $82 \pm 15.4$ & 0.429 \\
\hline $3^{\text {rd }}$ day & $80.67 \pm 8.68$ & $77.33 \pm 13.63$ & 0.263 \\
\hline $5^{\text {th }}$ day & $72.67 \pm 6.91$ & $77.86 \pm 15$ & 0.092 \\
\hline
\end{tabular}

Chi-square test p. value $<0.05 \quad *$ statistically significant $* *$ highly significant

Table(6):- Relationship between (Study \& Control group) according to Bleeding tendency post implementation of nursing instructions $(\mathbf{n}=60)$ :

\begin{tabular}{|c|c|c|c|c|c|c|c|c|c|c|c|c|c|}
\hline \multirow[t]{2}{*}{ Bleeding tendency } & & & \multicolumn{4}{|c|}{ Study group $\mathbf{n}=\mathbf{3 0}$} & \multicolumn{4}{|c|}{ control group $\mathbf{n}=\mathbf{3 0}$} & \multirow{2}{*}{\multicolumn{2}{|c|}{$5^{\text {th }}$ day }} & \multirow[t]{2}{*}{ P. value } \\
\hline & \multicolumn{2}{|c|}{$1^{\text {st }}$ day } & \multicolumn{2}{|c|}{$3^{\text {rd day }}$} & \multicolumn{2}{|c|}{$5^{\text {th }}$ day } & \multicolumn{2}{|c|}{$1^{\text {st }}$ day } & \multicolumn{2}{|c|}{$3^{\text {rd }}$ day } & & & \\
\hline \multicolumn{14}{|l|}{ External bleeding: } \\
\hline & n. & $\%$ & n. & $\%$ & n. & $\%$ & n. & $\%$ & n. & $\%$ & n. & $\%$ & \\
\hline $\begin{array}{ll}\begin{array}{l}\text { Injection } \\
\text { bleeding }\end{array} & \text { site } \\
\end{array}$ & 30 & 100.0 & 30 & 100.0 & 4 & 13.3 & 24 & 80 & 26 & 86.7 & 20 & 66.7 & \\
\hline Bleeding gum & 28 & 93.3 & 26 & 86.7 & 7 & 23.3 & 25 & 83.3 & 22 & 73.3 & 22 & 73.3 & $0.001 * *$ \\
\hline Epistaxis & 28 & 93.3 & 24 & 80.0 & 2 & 6.7 & 28 & 93.3 & 24 & 80.0 & 16 & 53.3 & \\
\hline \multicolumn{14}{|l|}{ Internal Bleeding: } \\
\hline Vaginal bleeding & 12 & 40.0 & 10 & 33.3 & 3 & 9.9 & 13 & 43.3 & 11 & 36.6 & 10 & 33.3 & \\
\hline Melena & 1 & 3.3 & 0 & 0.0 & 0 & 0.0 & 0 & 0.0 & 0 & 0.0 & 0 & 0.0 & \\
\hline hematemesis & - & - & - & - & - & - & - & - & - & - & - & - & $0.001 * *$ \\
\hline
\end{tabular}


Table (7): Relationship between (Study \& Control group) regarding to amount of blood loss according to shock classes post implementation of nursing instructions $(n=60)$.

\begin{tabular}{|l|c|c|c|c|c|}
\hline \multirow{2}{*}{ Shock classes (amount in ml) } & \multicolumn{2}{|c|}{ Study(n=30) } & \multicolumn{2}{|c|}{ Control(n=30) } & \multirow{2}{*}{ P. value } \\
\cline { 2 - 5 } & $\mathbf{n}$ & $\mathbf{\%}$ & $\mathbf{n .}$ & $\mathbf{\%}$ & \\
\hline Class I: $(750 \mathrm{ml})$ & 3 & 10.0 & 5 & 16.7 & \\
\hline Class II: $(750: 1500 \mathrm{ml})$ & 25 & 83.3 & 13 & 43.3 & \multirow{2}{*}{$0.008 * *$} \\
\hline Class III: (1500-2000ml) & 2 & 6.7 & 10 & 33.3 & \\
\hline Class IV: $(>2000 \mathrm{ml})$ & 0 & 0.0 & 2 & 6.7 & \\
\hline
\end{tabular}

- Chi-square test, $* *$ Significant difference at $\mathrm{p}$. value $<0.01$

Table (8): Relationship between (Study \& Control group) according to complications post implementation of nursing instructions $(\mathbf{n}=60)$.

\begin{tabular}{|c|c|c|c|c|c|}
\hline \multirow{2}{*}{ Complications } & \multicolumn{2}{|c|}{ Study $(n=30)$} & \multicolumn{2}{|c|}{$\operatorname{Control}(n=30)$} & \multirow{2}{*}{ P. value } \\
\hline & n. & $\%$ & n. & $\%$ & \\
\hline \multicolumn{6}{|l|}{ Anemia } \\
\hline $1^{\text {st }}$ day & 28 & 93.3 & 26 & 86.7 & 0.389 \\
\hline $3^{\text {rd }}$ day & 22 & 73.3 & 20 & 66.7 & 0.573 \\
\hline $5^{\text {th }}$ day & 10 & 33.3 & 20 & 66.7 & $0.010 *$ \\
\hline \multicolumn{6}{|l|}{ Hypovolemic shock } \\
\hline $1^{\text {st }}$ day & 18 & 60.0 & 22 & 73.3 & 0.273 \\
\hline $3^{\text {rd }}$ day & 8 & 26.7 & 18 & 60.0 & $0.009 * *$ \\
\hline $5^{\text {th }}$ day & 0 & 0.0 & 14 & 46.7 & $<0.001 * *$ \\
\hline
\end{tabular}

Chi-square test p. value $<0.05 *$ statistically significant $* *$ highly significant

Table(1): This table illustrates socio-demographic data of the study and control group. Regarding age, it was noticed that the main age in study and control

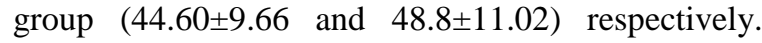
Related gender, the majority of patient of study group were male and control group were female $(53.3 \%$ and $66.7 \%)$ respectively.

Table(2): This table illustrates relationship between the study and control group according to medical data. Regarding past health history, the majority of the patients in the study group and control group had respiratory disease $(100.0 \%$ and $86.7 \%)$ respectively.

Table(3): This table illustrates the relationship between the study and control group according to Blood picture and illustrated that there were statistical difference between the study and control group in $\mathrm{RBC}$ at $5^{\text {th }}$ day with $(\mathrm{P}$. value $<0.001)$ and in hemoglobin at $5^{\text {th }}$ day with $(\mathrm{P}$. value $<0.014)$ and in Hematocrit at $5^{\text {th }}$ day with $(\mathrm{P}$. value $<0.001)$ and in Platelet at $1^{\text {st }}$ day with $(\mathrm{P}$. value 0.001$)$ and in WBCs at $5^{\text {th }}$ day with (P. value 0.041 ).

Table(4): This table illustrates relationship between study and control group according to coagulation profile and illustrated that there was statistical difference between the study and control group in Pc at $5^{\text {th }}$ day with $(\mathrm{P}$. value $<0.011)$ and in
INR at $3^{\text {rd }}$ and $5^{\text {th }}$ day with (P. value $\left.<0.046,0.001\right)$ respectively.

Table (5): This table illustrates the relationship between study and control group according to hemodynamic parameter, and illustrated that there was a statistical difference between study and control group in systolic blood pressure at $5^{\text {th }}$ day with $(\mathrm{P}$. value $<0.025)$

Table (6): This table illustrates the relationship between study and control group according to Bleeding tendency assessment and illustrated that there was a statistical difference between study and control group in bleeding at $3^{\text {rd }}, 5^{\text {th }}$ day with $(\mathrm{P}$. value $<0.001,0.001$ ) respectively.

Table (7): This table illustrates relationship between study and control group regarding amount of blood loss according to class of hemorrhagic shock. And illustrated that there were statistical difference between study and control group with (P. value $<0.008)$.

Table(8): This table illustrates the relationship between study and control group according to complications and illustrated that there was a statistical difference between study and control group in anemia at $5^{\text {th }}$ day with $(\mathrm{P}$. value $<0.010)$, and in hypovolemic shock at $3^{\text {rd }}, 5^{\text {th }}$ day with (P. value $<$ $0.009,0.001)$. 


\section{Discussion}

Patients with acute myeloid leukemia undergoing induction chemotherapy or suffer from bleeding which needs special nursing instructions to improve the patient outcome and reduce complication and bleeding tendency (Noesslinger et al., 2018).

Therefore, this study conducted aiming to investigate the effect of implementing nursing instructions to reduce bleeding among patients with Acute Myeloid Leukemia (AML) admitted to intensive care unit.

Socio-demographic characteristics of the studied group

Based on the results of the present study, the patient's socio-demographic data between the study and control groups were comparable and no significant differences were founded except marital status. This finding was agreeing with Schaepe \& Ewers, (2017) who reported that there were no significant differences in the age, gender, and other demographic and baseline characteristics between study and control groups.

Based on the results of the present study; more than half of the study and control groups aged 50 years and more. This agreed with Kuznetsova et al., (2016) who mentioned that the average age of acute myeloid leukemia was $48.9 \pm 18.3$ years old. Medinger \& Passweg, (2018) monitored that AML is now cured in approximately $35 \%-40 \%$ of patients younger than age 60 years old.

Majority of the patient in the study group were male and in the control group were female. This agrees with Shysh et al., (2018) who found that acute myeloid leukemia is most common in older people and affects males more than females.

\section{Medical data (past history):}

The present study revealed that; the majority of patients in the study and the control group had respiratory disease. In this finding, Matynia et al., (2018) reported that acute respiratory complications occur frequently during the early phase of acute myeloid leukemia (AML) but information on the most severe form. Moreau et al., (2014) confirmed this result when retrospectively analyzed clinical and laboratory data from 114 patients admitted to a medical ICU within 10 days after a diagnosis of AML suggesting a role as a preventive treatment in patients with AML-related non-infectious pulmonary involvement.

\section{Blood picture}

The current study illustrated that there was a statistical difference between study and control group in RBC, hemoglobin, hematocrit, platelet and WBCs at $5^{\text {th }}$ day. In this concern, Martinelli et al., (2017) found; after starting nursing care, nearly all the patients in each group achieved a significant hematological and cytogenetic response at 6 months. Moreover, Jin et al., (2017) observed regarding platelet and hemoglobin, percentage improvement of platelet was comparatively enhanced throughout the successive follow up at 3,6 and 9 months. For hemoglobin, percentage improvement was comparatively better in female patients at 6 and 9 months. Also reported in other studies that after starting special care, nearly all the patients in each group achieved a significant hematological and cytogenetic response at 6 months.

The current study demonstrated that was a statistical difference between study and control group in Prothrombin time, prothrombin concentration and international normalized ratio (INR) at $5^{\text {th }}$ day after application of nursing care. In this respects, Nguyen et al., (2016) mentioned that among all cancers, hematologic malignancy has the highest rate of intracranial hemorrhage. However, are limited data on intracranial hemorrhage in acute leukemia. Patients with ALL and hyper leukocytosis were more likely to develop hemorrhagic/vascular problems.

\section{Vital signs monitoring}

The current study demonstrated that there was a statistical difference between study and control group in temperature, and in heart rate by comparison of $1^{\text {st }}$ , $3^{\text {rd }}$ and $5^{\text {th }}$ day among study and control groups, systolic BP and diastolic BP. The data added that; there was a statistical stability in the hemodynamic status after application of the nursing care for studied patients.

The present study showed a decrease in the temperature level from fevered to normal level after $5^{\text {th }}$ day of guidelines application. This match with Verlinden et al., (2019) study who demonstrated that the presence of fever was significantly associated with AML and found that fever due to infection could not be reliably differentiated from fever not due to infection by either the height or character of the fever curve, or by counting the absolute number of mature leukocytes in the blood. Consideration of the fever of acute leukemia from the point of view of present day studies of the pathogenesis of fever did not implicate known mechanisms of pyogenesis.

\section{Bleeding tendency}

The data of the present study illustrated that there were statistical difference between study and control group in both internal and external bleeding at $1^{\text {st }}, 3^{\text {rd }}$, $5^{\text {th }}$, days and in bleeding at $3^{\text {rd }} \& 5^{\text {th }}$ days. In addition, the present study found that there were significant decreases in bleeding.

Chowdhri et al., (2018) found that more than half of the studied patients suffered from petechiae or bleeding the remaining sample suffered from 
ulceration were the most common initial diagnosis manifestation of leukemia in a 10-year retrospective study of patients.

\section{Amount of blood loss}

The current study illustrated the relationship between study and control group regarding amount of blood loss according to class of hemorrhagic shock. and illustrated that there were statistical difference between study and control group in addition, the present study showed that the majority of the studies groups were class (II) according to Shock class and amount of blood loss.

This not in the same line with Nanjappa et al., (2016) who found the proportions of patients alive at discharge whose primary ICU diagnosis was hemorrhagic shock of the studied AML patients.

In this respect Bower et al., (2016) found that majority of AmL were suffering from mild bleeding (grade 2to 3) is associated with the risk of severe bleeding. This is an important finding for several reasons. It provides support for the use of mild bleeding as a study outcome measure. Many clinicians feel that the only bleeding that is truly of consequence is bleeding of grade 3 or 4 in severity. However, if grade 1 and 2 bleeds are confirmed to be predictive of more severe bleeding, they may be able to be used as clinically relevant outcomes.

\section{Complications}

The current study illustrated that there was a statistical difference between study and control group in Anemia at $5^{\text {th }}$ days, and in Hypovolemic shock at $3^{\text {rd }}$ and $5^{\text {th }}$ days Misirlioglu et al., (2015) mentioned that; infections and anemia are the major causes of death in leukemic patients.

\section{Conclusion}

Based on the result of the present study, it was concluded that

- The bleeding tendency in study group who will receive nursing instructions will be less than control group who receive routine care at ICU.

- This study conclude that implementation of nursing instructions in the patients with acute myeloid leukemia leading to minimize bleeding, improve laboratory investigations, and stability in hemodynamic status.

\section{Recommendations}

Based on the findings of the present study, the following recommendations are derived:

- Continued nursing instructions at critical care units should be organized within south Egypt cancer institute.

- Adequate supplies and facilities should be available in the unit.
- Replication of the study on a larger probability sample acquired from different geographical area in Egypt to figure out the main aspects of this problem.

\section{References}

1. Bower, H., Andersson, T., Björkholm, M., Dickman, P., Lambert, P., \& Derolf, A., (2016): Continued improvement in survival of acute myeloid leukemia patients: an application of the loss in expectation of life. Blood cancer journal, 6(2), e390.

2. Chowdhri, K., Tandon, S., Lamba, A., \& Faraz, F., (2018): Leukemic gingival enlargement: A case report and review of literature. Journal of oral and maxillofacial pathology: JOMFP, 22(Suppl 1), S77.

3. Deep, A., \& Bunchman, T., (2015): 8 th International Conference on Pediatric Continuous Renal Replacement Therapy. Pediatr Nephrol, 30, 2221-2250.

4. Hatzl, S., Uhl, B., Hinterramskogler, M., Leber, S., Eisner, F., Haring, M., \& Jud, P. (2018): Acute myeloid leukemia with severe coagulation disorder and concomitant central nervous system bleeding-a clinical diagnostic case report. EJIFCC, 29(2), 146.

5. Iliescu, C., Grines, C., Herrmann, J., Yang, E., Cilingiroglu, M., Charitakis, K., ... \& Marmagkiolis, K., (2016): SCAI Expert consensus statement: Evaluation, management, and special considerations of cardio-oncology patients in the cardiac catheterization laboratory (endorsed by the cardiological society of india, and sociedad Latino Americana de Cardiologia intervencionista). Catheterization and cardiovascular interventions, 87(5), E202-E223.

6. Janice L, \& Kerry H., (2014): BRUNNER and SUDDARTHS text book of Medical Surgical Nursing.13th ed Chapter 34,Unit 7.pp 944.

7. Jin, L., Yu, H., Dong, T., Zhang, B., Yan, H., Liao, H., \& Zou, X., (2017): The Prognostic Value of ADP-Induced Platelet Aggregation for Bleeding Complications in Low-Intermediate Risk Patients with Acute Coronary Syndrome Taking Clopidogrel After Percutaneous Coronary Intervention. Heart, Lung and Circulation, 26(1), 49-57

8. Kuznetsova, I., Labutina, E., \& Hunter, N., (2016): Radiation risks of leukemia, lymphoma and multiple myeloma incidence in the Mayak cohort: 1948-2004. PloS one, 11(9), e0162710.

9. Leguit, R., \& Van Den Tweel, J., (2010): The pathology of bone marrow failure. Histopathology, 57(5), 655-670. 
10. Lewis, Dirksen, Heitkemper, \& Bucher, (2015): Medical Surgical Nursing assessment and management of clinical problem.2nd ed Chapter 31, Section 6, Elsevier volume 1. pp 696-697.

11. Martinelli, G., Boissel, N., Chevallier, P., Ottmann, O., Gökbuget, N., Topp, M. S., \& Sterling, L., (2017): Complete hematologic and molecular response in adult patients with relapsed/refractory Philadelphia chromosomepositive B-precursor acute lymphoblastic leukemia following treatment with blinatumomab: results from a phase II, single-arm, multicenter study. Journal of Clinical Oncology, 35(16), 1795-1802.

12. Matynia, A., Perkins, S. L., \& Li, D., (2018): Lymphomatoid granulomatosis in a 14-year-old boy with trisomy 21 and history of Blymphoblastic leukemia/lymphoma. Fetal and pediatric pathology, 37(1), 7-14.

13. Medinger, M., \& Passweg, J., (2018): What the internist should know about stem cell transplant in the elderly patient. European journal of internal medicine, 58, 43-47.

14. Misirlioglu, M., Adisen, M., \& Yilmaz, S., (2015): Diagnosis of acute myeloid leukemia in a dental hospital; report of a case with severe gingival hypertrophy. Nigerian journal of clinical practice, 18(4), 573-576.

15. Moreau, A., Lengline, E., Seguin, A., Lemiale, V., Canet, E., Raffoux, E., \& Azoulay, E., (2014): Respiratory events at the earliest phase of acute myeloid leukemia. Leukemia \& lymphoma, 55(11), 2556-2563.

16. Munshi, M., Florez, H., Huang, E., Kalyani, R., Mupanomunda, M., Pandya, N., \& Haas, L., (2016): Management of diabetes in long-term care and skilled nursing facilities: a position statement of the American Diabetes Association. Diabetes care, 39(2), 308-318.

17. Nanjappa, S., Jeong, D., Muddaraju, M., Jeong, K., Hill, E., \& Greene, J., (2016): Diffuse alveolar hemorrhage in acute myeloid leukemia. Cancer Control, 23(3), 272-277.

18. Nguyen, R., Jeha, S., Zhou, Y., Cao, X., Cheng, C., Bhojwani, D., ... \& Sandlund, J., (2016): The role of leukapheresis in the current management of hyperleukocytosis in newly diagnosed childhood acute lymphoblastic leukemia. Pediatric blood \& cancer, 63(9), 15461551.

19. Noesslinger, T., Panny, M., Simanek, R., Moestl, M., Boehm, A., Menschel, E., \& Keil, F., (2018): High-dose Bendamustine-EAM followed by autologous stem cell rescue results in long-term remission rates in lymphoma patients, without renal toxicity. European journal of haematology, 101(3), 326-331.

20.Schaepe, C., \& Ewers, M., (2017): 'I need complete trust in nurses'-home mechanical ventilated patients' perceptions of safety. Scandinavian journal of caring sciences, 31(4), 948-956.

21. Shysh, A. C., Nguyen, L., Guo, M., Vaska, M., Naugler, C., \& Rashid-Kolvear, F., (2018): The incidence of acute myeloid leukemia in Calgary, Alberta, Canada: a retrospective cohort study. BMC public health, 18(1), 94.

22. Verlinden, A., De Vroey, V., Goossens, H., Roelant, E., Van De Velde, A., Berneman, Z., \& Gadisseur, A., (2019): Comparison of the power of procalcitonin and c-reactive protein to discriminate between different aetiologies of fever in prolonged profound neutropenia: a singlecentre prospective observational study. Mediterranean journal of hematology and infectious diseases, 11(1). 